Supporting Information

\title{
Click Chemistry-Based Two-Component System for efficient inhibition of Human Immunodeficiency Virus (HIV) Reverse Transcriptase
}

\author{
Carlos E. Ledezma, Evan M. Cornett, Dmitry M. Kolpashchikov*
}

Department of Chemistry, University of Central Florida, 4111 Libra Drive, Orlando, Florida 32816, United States

\section{Table of Contents}

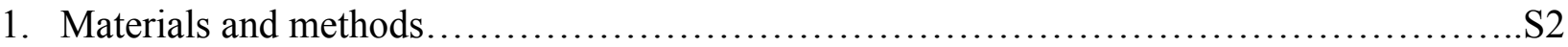

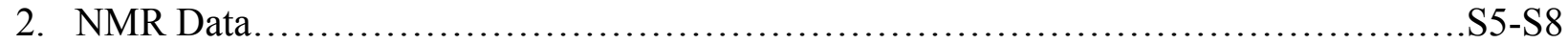

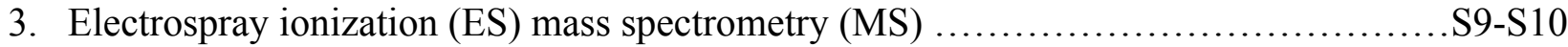




\section{Materials and methods}

Analogs of deoxythymidine-5'-triphosphate (dTTP) were synthesized from dUTP (SigmaAldrich, Missouri) and characterized as described below. Primer: 5'-GTC CCT GTT CGG GCG CCA and template: 5' - TGT GTG TGC GTT CTC GTT CTA TGG CGC CCG AAC AGG GAC were custom-made by Integrated DNA Technologies, Inc (Coralville, IA). T7 RNA polymerase was purchased from New England Biolabs (Ipswich, MA). HIV-1 RT was from Worthington Biochemical Corporation (Lakewood, NJ). Electrospray ionisation (ES) mass spectrometry (MS) was conducted by Florida University facilities.

\section{Synthesis of dTTP analogs.}

5-(Aminomethyl)-2'-deoxyuridine-5'-triphosphate, Triethylammonium salt (aadTTP) was synthesized by using the procedure by Langer et al.

Synthesis of 6-azidohexanoic acid: $1.94 \mathrm{~g}(10 \mathrm{mmol})$ of 6-bromohexanoic acid (ACROS) and $1.3 \mathrm{~g}(20 \mathrm{mmol})$ of sodium azide (ACROS) were added to $10 \mathrm{~mL}$ of previously dried N,Ndimethylformamide (ACROS). The solution was stirred at room temperature for $36 \mathrm{hr}$. The product was extracted with $15 \mathrm{~mL}$ of dichloromethane, and the organic layer was washed three times with $20 \%$ aqueous lithium chloride and dried over anhydrous magnesium sulfate overnight at $4^{\circ} \mathrm{C}$. The solvent was then evaporated under vacuum, and the product, a colorless oil, was characterized by ${ }^{1} \mathrm{H}-\mathrm{NMR}\left(400 \mathrm{MHz}, \mathrm{CDCl}_{3}, \mathrm{ppm}\right): 1.38(\mathrm{~m}, 2 \mathrm{H}) ; 1.59(\mathrm{~m}, 4 \mathrm{H}) ; 2.32$ (t, 2H); 3.23 (t, 2H); 10.47 (s, ${ }^{1} \mathrm{H}$ ) and ${ }^{13} \mathrm{C}-\mathrm{NMR}$ (ppm): 24.48; 26.47; 28.85; 34.18; 51.9; 180.00 (Yield: 71\%, $1.109 \mathrm{~g}$ ).

Synthesis of 5-allyl(6-azidohexanamide) dTTP (6Az-dTTP): 6-azidohexanoic acid (7.28 $\mu \mathrm{L}$ $46.6 \mu \mathrm{mol}$ ) was added to a $1 \mathrm{~mL}$ solution containing $\mathrm{N}$-hydroxysuccinimide (ACROS) $(5.9 \mathrm{mg}$, $51.3 \mu \mathrm{mol})$ and dicyclohexylcarbodiimide (ACROS) $(11.5 \mathrm{mg}, 56 \mu \mathrm{mol})$ in $1 \mathrm{~mL}$ N,Ndimethylformamide (ACROS). The solution was rocked for 30 minutes, and the solution was separated from dicyclohexylurea by centrifugation at $10000 \mathrm{rpm}$ for 5 minutes at $4{ }^{\circ} \mathrm{C}$. The supernatant was then transferred to a tube containing $200 \mu \mathrm{L}$ 5-allylamine dUTP $(58.3 \mathrm{mM}$ solution in DMF), and trimethylamine (ACROS) $(26.02 \mu \mathrm{L}, 186.6 \mu \mathrm{mol}$, distilled). The new reaction mixture was rocked for approximately $2 \mathrm{~h}$ when complete consumption of allylamine was observed by ninhydrin stain on TLC, $\mathrm{R}_{\mathrm{f}}=0.42$. The resulting product was purified by RP-HPLC (Water: $30 \%$ Acetonitrile gradient), $\mathrm{t}_{\mathrm{r}}=19 \mathrm{~min}\left(16.8 \%\right.$ acetonitile), and characterized by ${ }^{1} \mathrm{H}-\mathrm{NMR}$ (400 MHz, $\left.\mathrm{D}_{2} \mathrm{O}, \mathrm{ppm}\right): 1.41(\mathrm{~m}, 2 \mathrm{H}) ; 1.63(\mathrm{~m}, 4 \mathrm{H}) ; 2.34(\mathrm{t}, 2 \mathrm{H}) ; 2.43(\mathrm{~m}, 2 \mathrm{H}) ; 3.35$ (m, 3H); 3.94 $(\mathrm{m}, 1 \mathrm{H}) ; 4.24(\mathrm{~m}, 3 \mathrm{H}) ; 4.70(\mathrm{~m}, 2 \mathrm{H}) ; 6.34(\mathrm{~m}, 2 \mathrm{H}) ; 6.44(\mathrm{~m}, 1 \mathrm{H}) ; 7.93$ (s, 1H). ${ }^{31} \mathrm{P}-\mathrm{NMR}(\mathrm{ppm})$ : $-19.94(\beta) ;-10.71(\alpha) ;-4.83(\gamma)$ (Yield: 31\%).

Synthesis of 5-allyl (6- (11, 12- Didehydro - 5, 6 - dihydrodibenzo [b,f] azocine - 5 - yl) - 6 oxohexanamide) dTTP (DBCO-dTTP): Dibenzocyclooctyne-acid (Sigma) (12.5 mg, 37.4 mol) was added to a $1 \mathrm{~mL}$ solution containing N-hydroxysuccinimide (ACROS) $(4.8 \mathrm{mg}, 41.4 \mu \mathrm{mol})$ and dicyclohexylcarbodiimide (ACROS) $(9.3 \mathrm{mg}, 45 \mu \mathrm{mol})$ in $1 \mathrm{~mL} \mathrm{~N}, \mathrm{~N}$-dimethylformamide (ACROS). The solution was rocked for $30 \mathrm{~min}$, and the solution was separated from dicyclohexylurea by centrifugation at $10000 \mathrm{rpm}$ for 5 minutes at $4{ }^{\circ} \mathrm{C}$. The supernatant was then transferred to a tube containing $200 \mu \mathrm{L}$ 5-allylamine dUTP (46.8 mM solution in DMF), and 
diisopropylethylamine (ACROS) $(7.52 \mu \mathrm{L}, 74.8 \mu \mathrm{mol})$. The new reaction mixture was rocked for approximately $2 \mathrm{~h}$ when consumption of allylamine was observed by ninhydrin stain on TLC, Rf $=0.49$. The resulting product was purified by RP-HPLC, $\operatorname{tr}=33 \mathrm{~min}(30 \%$ acetonitrile), and characterized by ${ }^{1} \mathrm{H}-\mathrm{NMR}\left(400 \mathrm{MHz}, \mathrm{D}_{2} \mathrm{O}, \mathrm{ppm}\right): 1.13(\mathrm{~m}, 4 \mathrm{H}) ; 1.91-2.04(\mathrm{~m}, 4 \mathrm{H}) ; 2.33(\mathrm{~m}$, 2H); $4.16(\mathrm{~m}, 3 \mathrm{H}) ; 4.60(\mathrm{~m}, 1 \mathrm{H}) ; 6.25(\mathrm{~m}, 2 \mathrm{H}) ; 7.12(\mathrm{~m}, 1 \mathrm{H}) ; 7.35(\mathrm{~m}, 4 \mathrm{H}) ; 7.56(\mathrm{~m}, 1 \mathrm{H}) ; 7.76$ (m, 1H). ${ }^{31}$ P-NMR (ppm): - $19.97(\beta) ;-10.74(\alpha) ;-5.01(\gamma)$ (Yield: 19\%).

3. Substrate Properties of dTTP analogs and PAGE analysis. The substrate properties were tested by incubating $30 \mu \mathrm{L}$ sample containing $5 \mu \mathrm{M}$ dTTP or dTTP containing fluorescein labeled primer in complex with template $(1 \mu \mathrm{M})$, HIV-RT $(50 \mathrm{nM})$ in reaction buffer $(50 \mathrm{mM}$ Tris-HCl $\mathrm{pH}=8,100 \mathrm{mM} \mathrm{KCl}, 8 \mathrm{mM} \mathrm{MgCl}_{2}$, BSA $100 \mathrm{mg} / \mathrm{mL}$, and DTT $2 \mathrm{mM}$ ). After incubation $30 \mathrm{~min}$ at $37^{\circ} \mathrm{C}, 1.5 \mu \mathrm{L} \mathrm{dVTPs}(\mathrm{dATP}, \mathrm{dCTP}$, and dGTP) to the final concentration of $5 \mathrm{mM}$ were added to $15 \mu \mathrm{L}$ aliquot of the previously incubated mixture for substrate properties, while $1.5 \mu \mathrm{L}$ of the second analog was added to the $30 \mu \mathrm{L}$ inhibition property samples. The reaction mixtures were incubated for additional $30 \mathrm{~min}$ (dVTP-containing) or $20 \mathrm{~min}$ (second analog-containing) at $37^{\circ} \mathrm{C}$. The inhibition samples were then aliquoted into two samples containing $15.75 \mu \mathrm{L}$, and $1.5 \mathrm{~mL}$ of dNTPs were added to one of the aliquots and incubated for $30 \mathrm{~min}$ at $37{ }^{\circ} \mathrm{C}$. All reactions were quenched by the addition of loading buffer ( $70 \%$ formamide, $0.05 \%$ bromophenol blue, $29.95 \%$ glycerol, and $20 \mathrm{mM}$ EDTA) upon their respective final incubation. The reaction mixtures were then boiled for 5 minutes in a water bath and added to a $15 \%$ dPAGE gel. The gel was run at 400 $\mathrm{V}$ for $50 \mathrm{~min}$ at $55^{\circ} \mathrm{C}$. To demonstrate that inhibition was due to the incorporation of the analog and the subsequent click-reaction, a dPAGE gel was run by using a control sample containing dTTP where the dNTPs were added at the same time when dNTPs were added to the inhibition samples, after $50 \mathrm{~min}$ of incubation. 
4. Filter binding assay (FBA) Analysis of Elongation, Inhibition, and Specificity. A filter binding assay (FBA) was employed to quantify primer elongation by dNTPs after the addition of dTTP, analogs, and TCCI combinations. For the FBA, a master mix containing fluorescein-labeled primer/template $(1 \mu \mathrm{M})$, HIV-RT $(50 \mathrm{nM})$, BSA $100 \mu \mathrm{g} / \mathrm{mL}$, DTT $(2 \mathrm{mM})$, and HIV-RT buffer was aliquoted into six $15 \mathrm{~mL}$ portions: Sample 1 (negative control), samples 2, 3, and 4 (dTTP, 6Az-dTTP, and DBCO-dTTP respectively), and samples 5 and 6 (6Az-dTTP and DBCOdTTP). The samples were incubated for $45 \mathrm{~min}$ at $37^{\circ} \mathrm{C}$. After the first step elongation, $15 \mathrm{~mL}$ of FBA master mix ( $1 \mathrm{mM}$ dTTP, $1 \mathrm{mM}$ dATP, $1 \mathrm{mM}$ dCTP, and $10 \mathrm{mM}{ }^{3} \mathrm{H}$-dGTP) was added to samples 1 through 4 and incubated for an additional $45 \mathrm{~min}$, while DBCO-dTTP was added to sample 5 and 6Az-dTTP was added to sample 6 and incubated for $30 \mathrm{~min}$. After the $30 \mathrm{~min}$ elapsed, FBA master mix was added to samples 5 and 6 , and further incubated for $45 \mathrm{~min}$, while samples 1 through 4 were quenched by the addition of $30 \mathrm{~mL}$ of $0.5 \mathrm{M}$ EDTA and placed on ice. All samples were then added to anion exchange filter papers (Whatman DE-80) and allowed to air dry. The dried filter papers were then washed twice with two $50 \mathrm{~mL}$ portions of $0.5 \mathrm{M}$ sodium phosphate buffer at $\mathrm{pH} 6.8$, followed by one ethanol wash. After washing, the filter papers were dried followed by transferring in $25 \mathrm{~mL}$ scintillation vials containing $7 \mathrm{~mL}$ of BD scintillation cocktail. Radiation was then measured by a scintillation counter (Beckmann 5900), and the reported values in counts per minute (CPM) were normalized to the value given by sample 2, which contains natural substrates. The experiment was run in triplicate to ensure statistical significance and normalized to the elongation of natural dNTPs. 
6. NMR Data
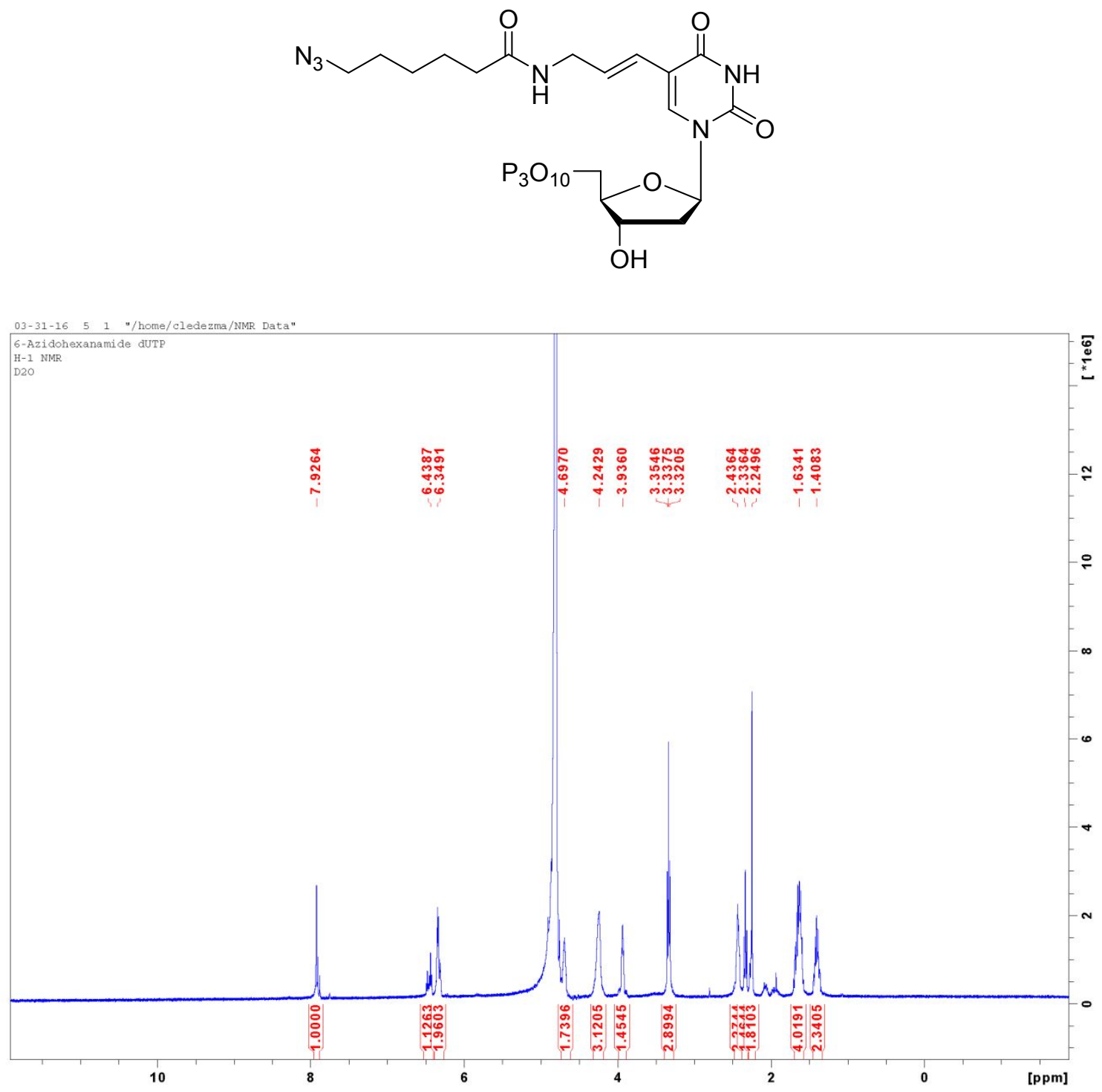

Figure S1. ${ }^{1} \mathrm{H}-\mathrm{NMR}$ for 6Az-dTTP. 


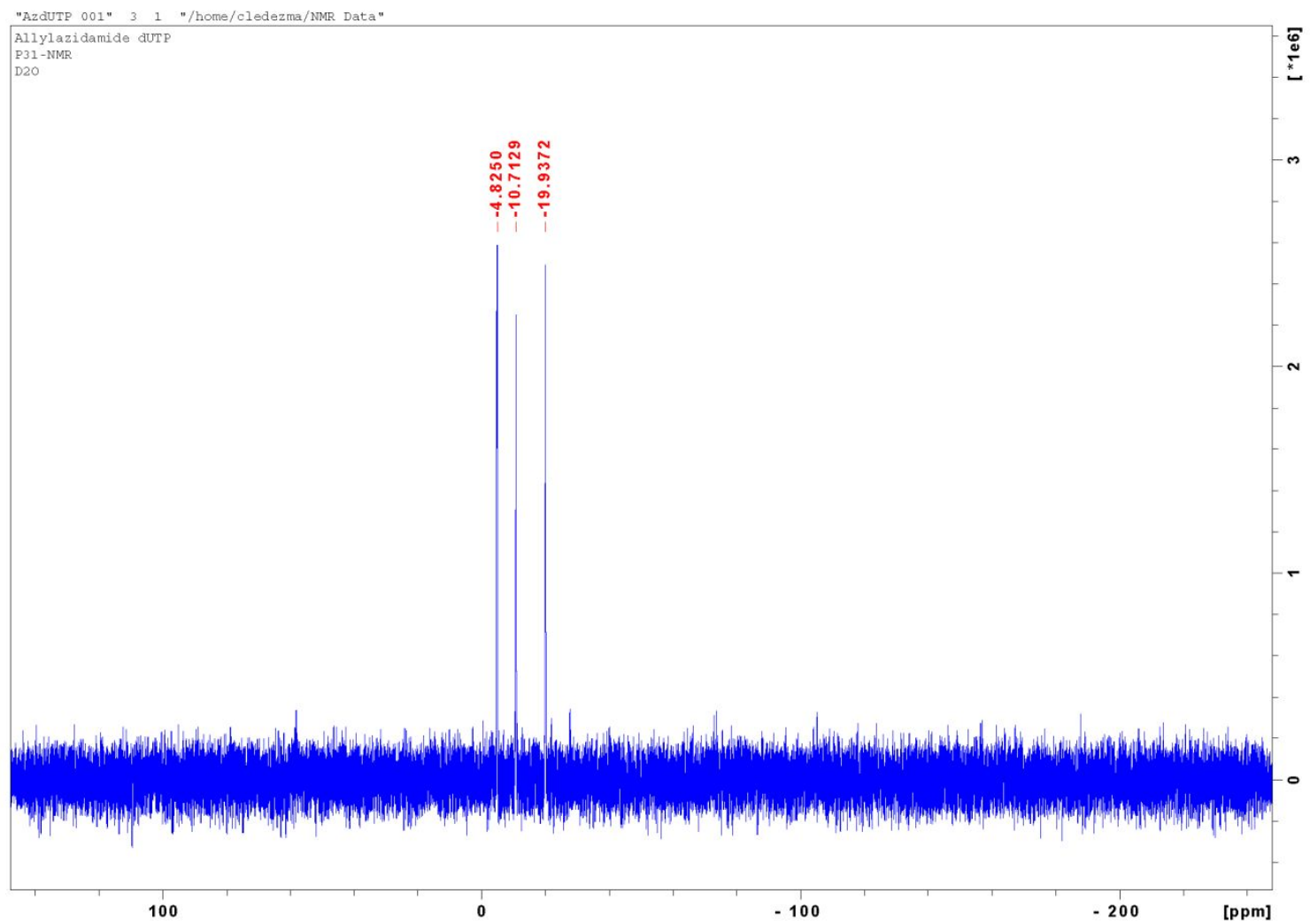

Figure S2. ${ }^{31} \mathrm{P}$ NMR for 6Az-dTTP. 

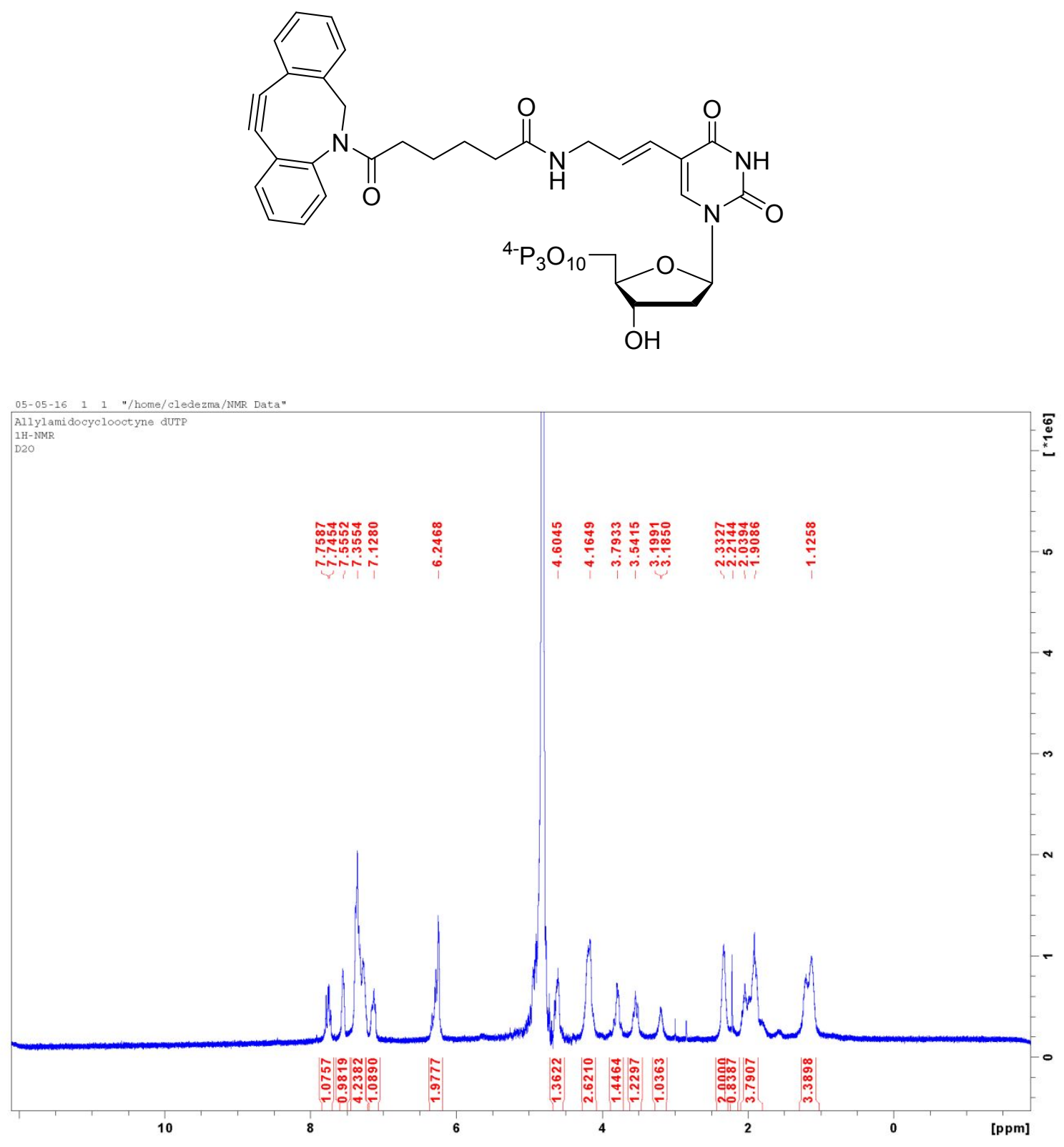

Figure S3. ${ }^{1} \mathrm{H}-\mathrm{NMR}$ for DBCO-dTTP. 


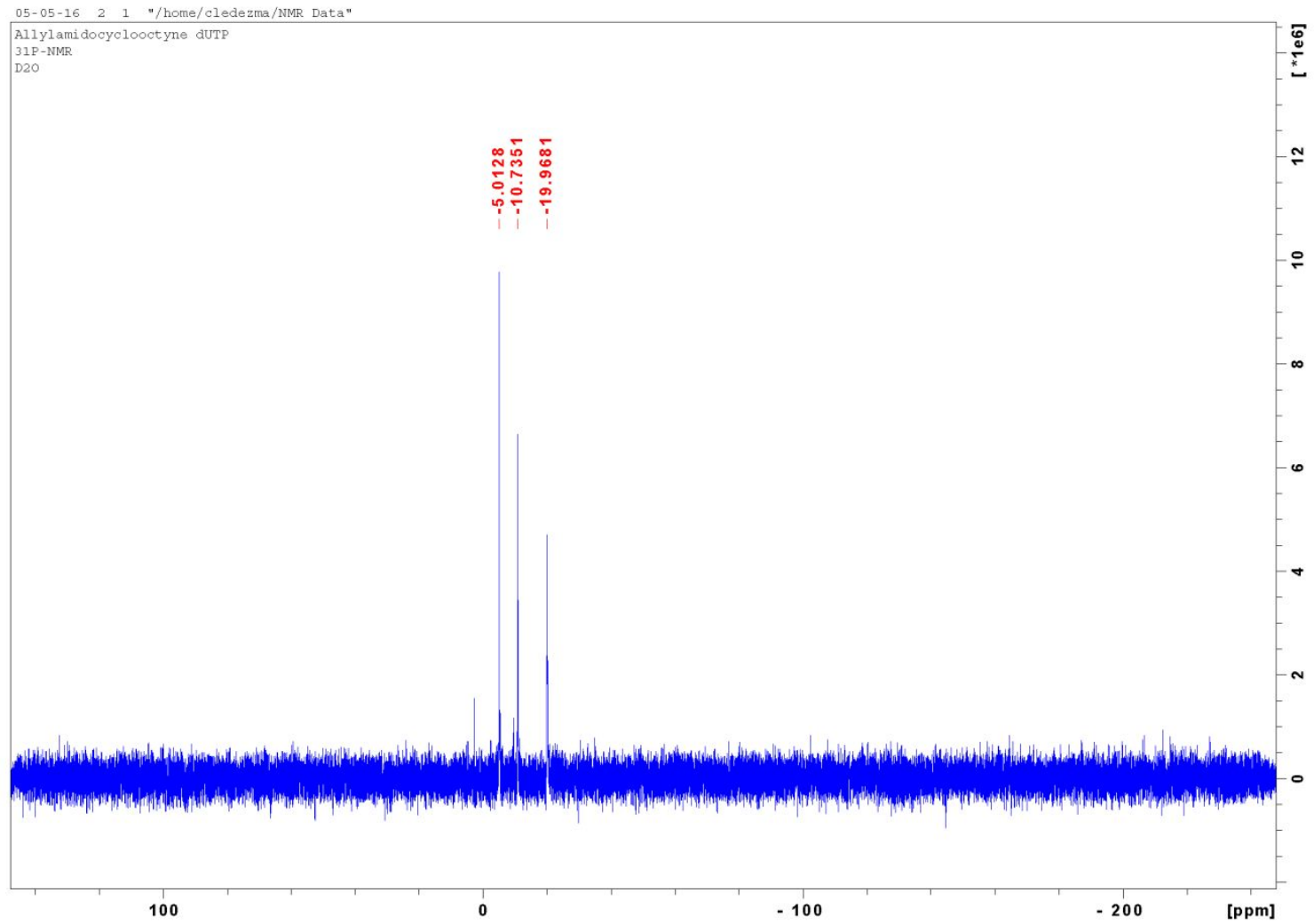

Figure $54 .{ }^{31} \mathrm{P}$ NMR for DBCO-dTTP. 
3. Electrospray ionization (ES) mass spectrometry (MS)

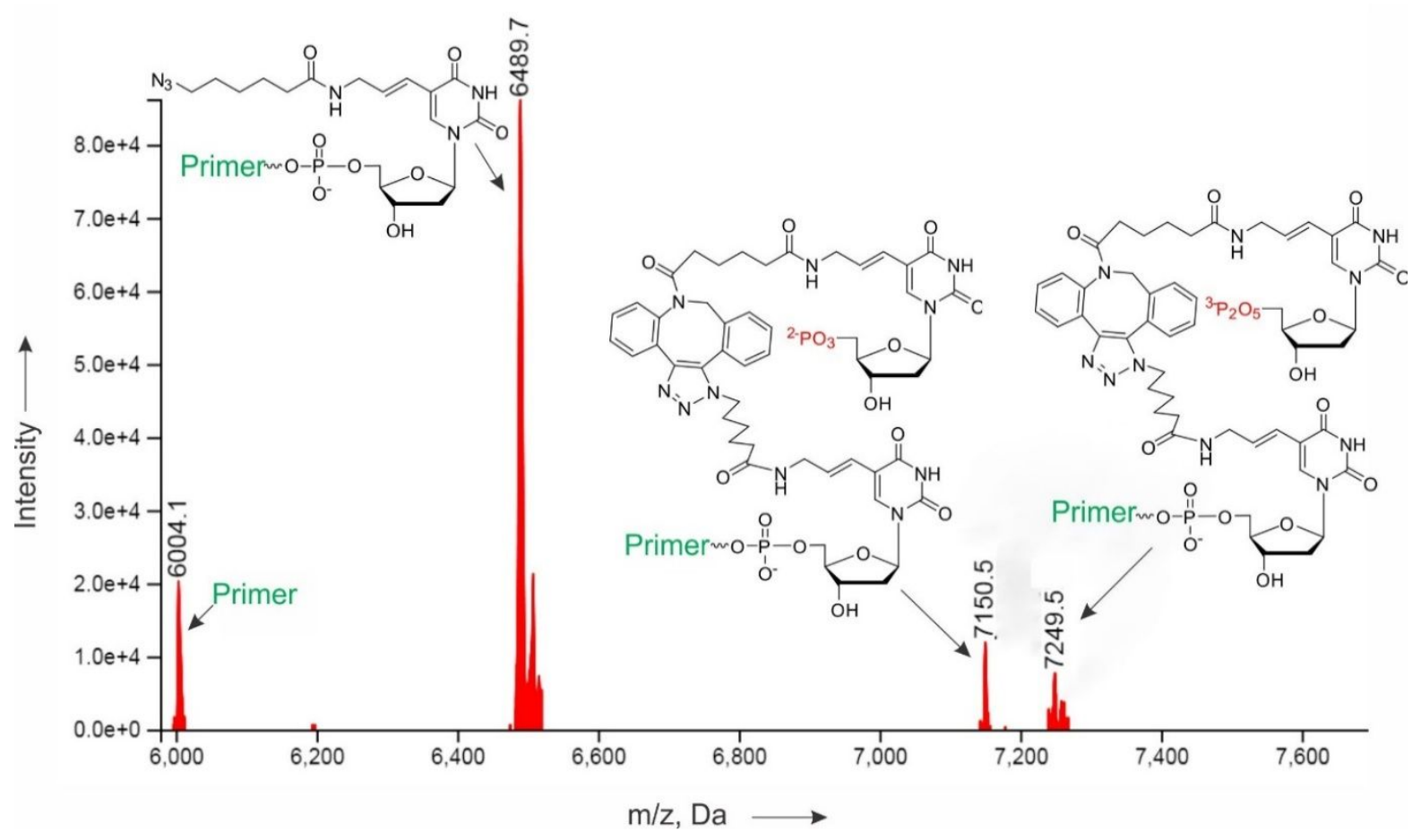

Figure S5. Electrospray ionization mass spectrum of $\mathrm{P} / \mathrm{T}$ elongated by HIV-1 RT in the presence 6Az-dTTP, following by addition of DBCO-dTTP (Lane 8 in Figure 1). The two click products $\mathrm{m} / \mathrm{z} 7150$ and 7249 were monophosphate and diphosphate derivative, the products of triphosphate group degradation during sample manipulation. 


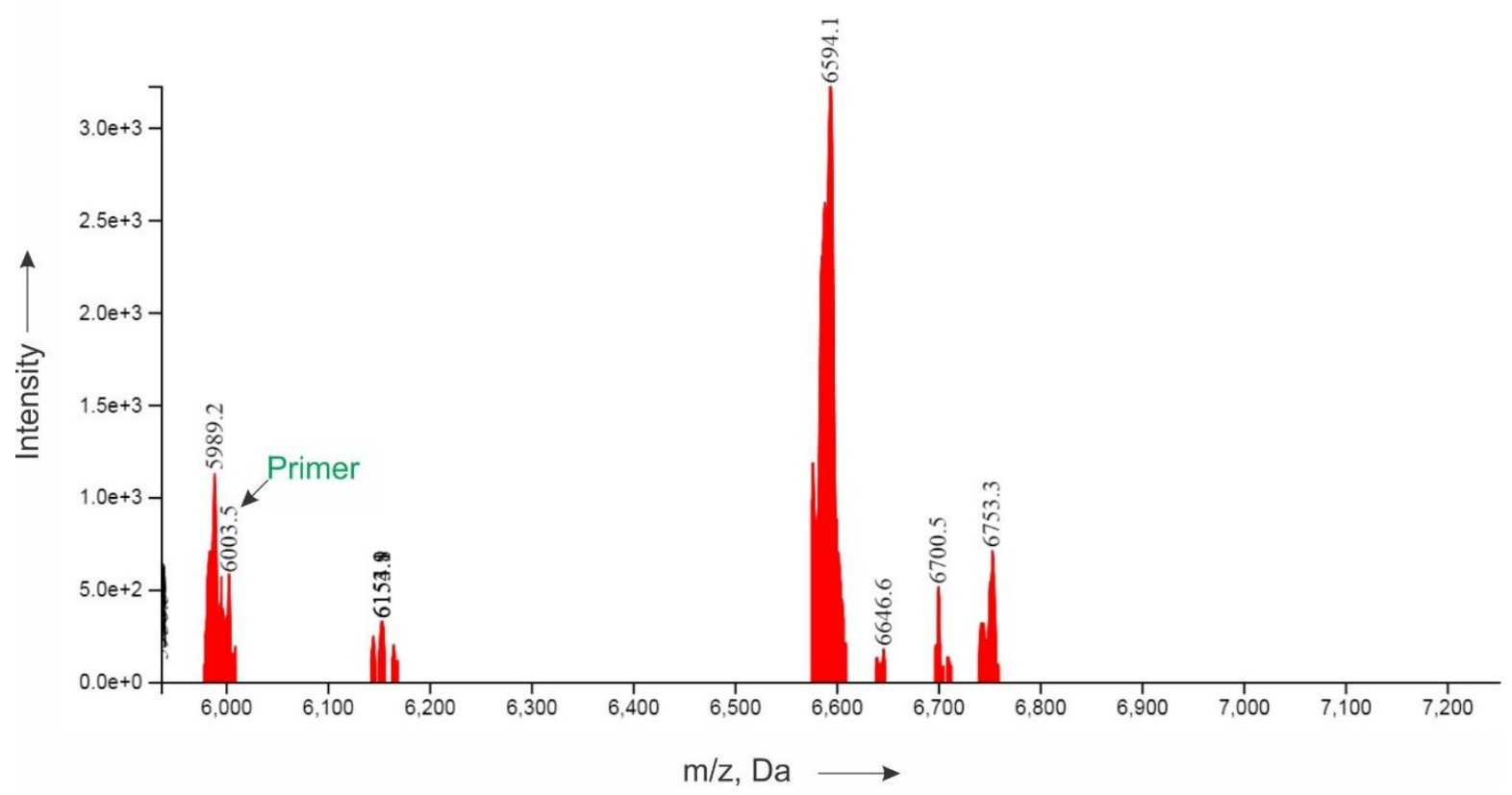

Figure S6. Electrospray ionization mass spectrum of P/T elongated by HIV-1 RT in the presence DBCO-dTTP, following by addition of 6Az-dTTP (Lane 10 in Figure 1). The main band 6594.1 $\mathrm{Da}$ does not correspond to the predicted 6694 Da predicted for DBCO-dTMP elongated primer or the 7150 and 7249 click products. 